\title{
Los marcadores interrogativos de control de contacto en el corpus PRESEEA de Santiago de Chile*
}

\author{
Abelardo San Martín Núñez** \\ Universidad de Chile
}

\begin{abstract}
Resumen
El objetivo de este trabajo es realizar una aproximación variacionista a un tipo específico de marcador del discurso en el español hablado en Santiago de Chile: los marcadores interrogativos de control de contacto. Para tal propósito, se identificaron las partículas que cumplían la mencionada función en una muestra de 54 entrevistas que conforman el Corpus Sociolingüístico de PRESEEA en Santiago de Chile. Por un lado, se analiza el comportamiento de este tipo de marcadores en la variedad antes indicada y, por otro, se establece la distribución de su empleo en una muestra socialmente estratificada de hablantes santiaguinos. Para el estudio de dichas partículas se aplicaron el concepto y la clasificación de los marcadores del discurso de Briz (2001), Martín Zorraquino y Portolés (1999) y Portolés (2001), así como las sugerencias de Cortés (1988) para su análisis cuantitativo. En el análisis se consideró la función “marcador
\end{abstract}

${ }^{*}$ En este artículo se presentan resultados parciales del Proyecto VID SOC 09/18-2, "Variación sintáctica y discursiva del español de Santiago de Chile", financiado por la Vicerrectoría de Investigación y Desarrollo de la Universidad de Chile.

** Para correspondencia, dirigirse a: Abelardo San Martín Núñez (asmartin@uchile.cl), Departamento de Lingüística, Facultad de Filosofía y Humanidades, Universidad de Chile, Ignacio Carrera Pinto 1025, Tercer Piso, Ñuñoa, Santiago, Chile. 
interrogativo de control de contacto" como un caso de variable sociolingüística con uno o más valores o variantes (marcadores). Consecuentemente, se correlacionaron los factores sociodemográficos de los sujetos con el empleo de dichos marcadores. De este modo, basándonos en la conmutabilidad funcional - pragmática y discursivade los marcadores relevados se procedió a su análisis cuantitativo, según las variables: edad, sexo-género y nivel educacional de los sujetos entrevistados.

Palabras clave: análisis del discurso, marcadores del discurso, función fática, variación discursiva, sociolingüística, español de Chile.

\title{
INTERROGATIVE MARKERS OF CONTACT CONTROL IN THE PRESEEA corpus of Santiago, Chile
}

\begin{abstract}
The aim of this paper is to approach from a variationist point of view a specific type of discursive markers in spoken Spanish in Santiago de Chile: interrogative markers of contact control. For this purpose, we identified the particles that perform that function in a sample of 54 interviews that make up the PRESEEA Sociolinguistic Corpus in Santiago, Chile were. On the one hand, we analyzed the behavior of such markers in the variety of Chilean Spanish indicated above and, on the other hand, we established their distribution in a socially stratified sample of Santiago speakers. For the study of these particles, we applied Briz (2001), Martin Zorraquino and Portolés (1999) and Portolés (2001) concepts and classifications of discourse markers, and the suggestions of Cortes (1988) for quantitative analysis. The analysis considered the «interrogative marker of contact control» as a sociolinguistic variable with one or more values or variants (markers). Consequently, socio-demographic factors were correlated with the subjects' use of such markers. Thus, based on the functionalpragmatic commutability of the discourse markers found in the interviews we carried out a quantitative analysis according to the variables age, sex, gender and educational level of the interviewees.
\end{abstract}

Key words: discourse analysis, discourse markers, phatic function, discursive variation, sociolinguistics, Chilean Spanish.

Recibido: 15/08/2011. Aceptado: 30/10/2011. 


\section{INTRODUCCIÓN}

\section{1. Naturaleza, objetivos y alCance del estudio}

Los marcadores del discurso constituyen un grupo de partículas que -característicamente- cumplen una función extra-oracional a nivel pragmático controlando la situación de enunciación, organizando la información discursiva o guiando la interpretación de los enunciados. El estudio de estas partículas, también denominadas conectores, muletillas, enlaces u ordenadores, ha suscitado un creciente interés en varias lenguas, desde diferentes puntos de vista, a partir de los trabajos iniciales en inglés (Sinclair y Coulthard 1972, Stubbs 1983 y Schiffrin 1987). De esta manera, los marcadores del discurso se han transformado en una fructífera temática de estudio dentro del amplio dominio del análisis del discurso. En este trabajo realizaremos una aproximación variacionista a un tipo específico de marcador del discurso en el español coloquial de Santiago de Chile: los marcadores interrogativos de control de contacto. El objetivo general de este estudio es analizar el comportamiento pragmático y la estratificación sociolingüística del empleo de dichos marcadores de función fática y forma interrogativa en el español coloquial de Santiago de Chile. Para tal propósito, se identificaron las partículas que cumplían la mencionada función en una muestra de 54 entrevistas que conforman el corpus del Proyecto para el Estudio Sociolingüístico del Español de España y América (PRESEEA) correspondiente al habla de Santiago de Chile. Nuestros objetivos específicos son, por un lado, identificar la función que dichas partículas desempeñan en el discurso más allá de su valor gramatical y, por otro, determinar su frecuencia de uso en un corpus de entrevistas sociolingüísticas realizadas a una muestra de hablantes santiaguinos socialmente estratificados.

\section{MARCO CONCEPTUAL}

2. 1. El ESTUdio de Los MARCAdORES DEL Discurso EN ESPAÑOL

En español, además del estudio de los enlaces extraoracionales de Gili Gaya (1972) y de Fuentes (1996), contamos con excelentes obras de carácter general sobre los marcadores del discurso como las de Martín Zorraquino y Montolío (coords. 1988), Martín Zorraquino y Portolés 
(1999), Portolés (2001) y Loureda y Acín (coords. 2010), entre otras. En especial, el estudio de los marcadores del discurso se ha concentrado en la definición y caracterización de estos elementos conectores, así como en la clasificación de las diversas funciones pragmáticas que cumplen en el discurso. Asimismo, existe una serie de monografías que abordan particularmente el funcionamiento discursivo de algunos de los marcadores del discurso en español ${ }^{1}$.

En relación con la definición y delimitación funcional de los marcadores del discurso, Portolés señala que,

Los marcadores del discurso son unidades lingüísticas invariables, no ejercen una función sintáctica en el marco de la predicción oracional y poseen un cometido coincidente en el discurso: el de guiar, de acuerdo con sus distintas propiedades morfosintácticas, semánticas y pragmáticas, las inferencias que se realiza en la comunicación (Portolés 2001: 25-26).

Para la clasificación de los marcadores en lengua española de acuerdo con su función, resultó fundamental la consulta de las clasificaciones de Martín Zorraquino y Portolés (1999) y Portolés (2001). Este último propone los siguientes tipos de marcadores discursivos (adaptado de Portolés, 2001: 146):

1. Estructuradores de la información (comentadores, ordenadores y digresores)

2. Conectores (aditivos, consecutivos y contraargumentativos)

3. Reformuladores (explicativos, de rectificación, de distanciamiento y recapitulativos)

4. Operadores discursivos (de refuerzo argumentativo, de concreción y de formulación)

5. Marcadores de control de contacto.

En especial, para efectos de la presente investigación, son pertinentes los tipos de partículas que Martín Zorraquino y Portolés (1999) llaman enfocadores de la alteridad y que Portolés (2001) denomina, siguiendo a Briz (2001), Marcadores de control de contacto, los que, en palabras de este último autor, se refieren a partículas de tipo metadiscursivo que:

manifiestan la relación entre los participantes de la conversación, sujeto y objeto de la enunciación, y de éstos con sus enunciados [...] refuerzan o

1 Cortés 1995a y 1995b ofrece una nutrida bibliografía sobre el estudio de los marcadores del discurso en varias lenguas. 
justifican los razonamientos de los hablantes ante su(s) interlocutores(es), sean argumentos o conclusiones; bien como retardos para mantener o comprobar el contacto; o como fórmulas exhortativas y apelativas que implican activamente al interlocutor (Briz 2001: 224-225).

Pertenecen a este grupo de marcadores, algunas partículas de forma interrogativa (con entonación ascendente) como ¿no?, ¿e?, ¿a?, ¿sí?, ¿entiendes?, ¿verdad?, ¿sabes? y otros de forma afirmativa (con entonación descendente) como oye, escucha, mira, fijate, entre otras. En este trabajo, como ya señalamos, nos concentraremos en el estudio de los marcadores de contacto con forma interrogativa que, funcionalmente, desde el punto de vista pragmático-discursivo, mantienen el contacto y controlan la comprensión del interlocutor, por lo tanto, cumplen la "función fática" del lenguaje (Jakobson 1975), más específicamente, el "mantenimiento de la atención interlocutiva" (Casado Velarde 1988: 65). Nuestro concepto de "marcador interrogativo de control de contacto", por lo tanto, se restringe a aquellas partículas periféricas con forma interrogativa y de valor metadiscursivo, mediante las cuales los hablantes mantienen la atención y controlan la comprensión del resto de los participantes en un intercambio comunicativo.

El estudio de este tipo específico de unidades del discurso en lengua española se ha realizado en el marco de obras de carácter más general. Por una parte, Fuentes estudia la función fática (1990a) y la función apelativa (1990b) de algunos operadores o "muletillas" en el español de Sevilla desde el punto de vista sociolingüístico. Para nuestro estudio, resultó particularmente pertinente el trabajo de Fuentes (1990b), en el cual se estudian algunas partículas mediante las cuales se apela al oyente solicitando su colaboración en el desarrollo del intercambio. Por otra parte, algunas de estas partículas han sido estudiadas en términos de "apéndices comprobativos o justificativos" por Ortega (1985 y 1986, respectivamente) o, recurriendo a la denominación en inglés de este tipo de partículas, como "preguntas confirmatorias" (tag questions) por Móccero (2010), destacando su valor como apéndices mediante los cuales los hablantes intentan comprobar o confirmar la aceptación de sus propias afirmaciones u opiniones por parte de los interlocutores ${ }^{2}$. No obstante el interés de la polivalencia funcional de

\footnotetext{
Móccero (2010), en particular, estudia el valor de las partículas ¿no? y ¿sí? como marcadores de posicionamiento intersubjetivo en una muestra de conversaciones en español de Argentina, en el marco de la Teoría de la Valoración de Martin y White (2005). Asimismo, Ramírez Gelbes (2003) estudia el contenido procedimental de la partícula "eh" bajo la Teoría de la Relevancia de Sperber y Wilson (1994), también con base en muestras del español
} 
estas partículas, es importante destacar que el objeto de análisis del presente estudio se limita al empleo de marcadores como ¿no?, ¿sí? o ¿cierto? solo en su función fática o de control de la intercomprensión del interlocutor en el intercambio. A este respecto, resultó de gran utilidad la consulta de Rodríguez (2009) que distingue las funciones pragmáticas de ¿no? y ¿eh? en una muestra del español hablado, destacando el funcionamiento fático de dichas partículas, más allá de su mero valor comprobativo.

Por lo que se refiere al estudio de las "muletillas" o de los marcadores del discurso en el español hablado en Chile, contamos con los trabajos de Rabanales y Contreras (1995), Pons y Samaniego (1998), Pérez (1998), Poblete (1998 y 1999), Meneses (2000) y González et al. (2000), entre otros. Rabanales y Contreras (1995) estudian las funciones de las muletillas en el habla culta de Santiago de Chile, entre las cuales incluyen las de función fática (oye, mira, ¿no es cierto?, ¿no?, ¿ah?, ¿mm? y ¿ves tú?). Además de proporcionar una clasificación de las funciones de las muletillas en una muestra de diálogos informales de hablantes cultos, los autores entregan datos cuantitativos sobre su empleo, según las variables: edad y sexo, resultando ser los jóvenes y los hombres los que más emplean muletillas. Por otro lado, Pons y Samaniego (1998) estudian los marcadores de apoyo empleados en una muestra de discurso oral de hablantes cultos de Santiago de Chile. Se analizan 29 marcadores de apoyo discursivo, según tres grupos etarios y la variable sexo (mujer/hombre) en el discurso de 10 sujetos. Los conectores textuales a nivel de parágrafo, por otra parte, se describen en Pérez (1998), quien señala que el tipo de texto (expositivo o argumentativo) en el parágrafo influye en los conectores empleados. Más allá de la descripción del habla capitalina, Poblete (1998 y 1999) estudia los marcadores del discurso empleados en Valdivia. En el primero de dichos trabajos, la autora identifica los marcadores conversacionales más frecuentes en una muestra representativa del habla de Valdivia compuesta por entrevistas semiformales. Se describen 75 marcadores conversacionales de acuerdo con su función y frecuencia de uso, sin embargo no se formulan observaciones respecto de la influencia de variables sociodemográficas. Posteriormente, en Poblete (1999) se estudian la distribución y ocurrencia de los marcadores que establecen coherencia (llamados "relacionantes") en secuencias discursivas de diferente tipo (descriptiva, narrativa, expositiva y argumentativa), presentes en 18 entrevistas semiformales. Los resultados obtenidos respecto de dicha

argentino. Por su parte, García Vizcaíno (2005) investiga las diferencias entre los apéndices moralizadores ¿no? y ¿eh? en el español peninsular a la luz de los estudios de la cortesía verbal. 
distribución por tipo de discurso se relacionaron con las variables sociales: estrato social, sexo y edad. Por otro lado, Meneses (2000) y González et al. (2000) plantean discusiones bibliográficas en torno a los marcadores discursivos característicos de la conversación coloquial.

Uno de los aspectos aún en desarrollo en la investigación de los marcadores del discurso en lengua española es la dimensión social y dialectal de su uso. En efecto, más allá de las referencias a la posibilidad de incorporar una perspectiva diastrática en Gili Gaya (1972), en los últimos años se han realizado estudios por comunidades como el de Obregón (1985) sobre los marcadores interaccionales en el español de Venezuela, el de Cortés (1991) sobre los marcadores discursivos empleados en León, el de Fuentes (1993) sobre los conectores en el habla de Sevilla o el de Rodríguez (1999) sobre los marcadores discursivos en Baranquilla, así como trabajos sobre marcadores específicos, entre los que destacamos los de Serrano (1995, 1999 y 2001). Con todo, las investigaciones de conjunto que aborden la distribución social y espacial de estos enlaces extra-oracionales de manera sistemática, en el dominio hispánico, están todavía en ejecución ${ }^{3}$.

\subsection{EL CONCEPTO DE VARIABLE SOCIOLINGǗ́STICA Y EL} ESTUDIO DE LOS MARCADORES DEL DISCURSO

En este estudio sugerimos la posibilidad de considerar a los marcadores del discurso como un caso de variable lingüística -en un sentido amplio del concepto- a nivel de discurso. Un aspecto a considerar, entonces, es el problema del análisis cuantitativo y sociolingüístico de este tipo de expresiones, lo que implicaría la extensión del ámbito de aplicación del concepto de variable sociolingüística más allá del plano fonético. Dicha problemática ha estado en el centro de la discusión sociolingüística,

\footnotetext{
Para una revisión crítica de los estudios sobre la variación dialectal y social de los marcadores del discurso recomendamos a Carbonero y Santana (2010). En opinión de los mencionados autores: "El estudio de las relaciones entre los marcadores del discurso y la procedencia espacial así como los rasgos sociales de los hablantes que los emplean, a juzgar por las referencias bibliográficas existentes y por la mención que se ha hecho a trabajos de esta naturaleza en revisiones críticas sobre esta temática, no es una de las principales perspectivas que ha ocupado a los estudiosos de estas unidades lingüísticas. No obstante, la revisión que hemos hecho en estas páginas es buena muestra de que es una línea de trabajo que ha aportado interesantes datos para un mejor conocimiento de tales elementos" (Carbonero y Santana 2010: 516-517).
} 
especialmente, a partir de los estudios de variación sintáctica en el inglés, el francés de Montreal y el español ${ }^{4}$, entre otras lenguas.

Como es sabido, una variable sociolingüística es un fenómeno de variación lingüística en que los valores o variantes de la variable están correlacionados con alguno de los factores sociodemográficos de los hablantes o de la situación de habla. Una exigencia para la aplicación de este concepto es que las formas alternantes no conlleven diferencias semánticas y, de esta manera, consistan de acuerdo con el precepto laboviano en "dos maneras diferentes de decir lo mismo". De hecho, la variación sociolingüística ha sido definida como "la alternancia de dos o más expresiones de un mismo elemento, cuando ésta no supone ningún tipo de alteración o cambio de naturaleza semántica y cuando se ve condicionada por factores lingüísticos y sociales" (Moreno Fernández 1998: 33), en cuyo caso, la variable puede tener significación social o estilística. Esto implica que, si se trata simplemente de un caso de variación en el lenguaje pero sin significación social o situacional, "la variación es solo de carácter lingüístico; no existe variación sociolingüística. Es evidente que este tipo de variación, independiente de los contextos sociales, carece de interés para la sociolingüística" (López Morales 2004: 150). Como vemos, solo cuando puede correlacionarse una variable lingüística con factores extralingüísticos del contexto socio-situacional, hablamos de "variable sociolingüística".

En un comienzo, los procedimientos y métodos de la sociolingüística se aplicaron con gran éxito en el estudio de la variación a nivel fonético, lo que se tradujo en una extensa serie de trabajos que abordaban, en particular, variables sociolingüísticas de naturaleza fonética (cf. López Morales 2004: 68). Sin embargo, la extensión del concepto de variable sociolingüística al estudio de fenómenos de variación sintáctica del inglés estadounidense y del francés de Montreal planteó una serie de dificultades, especialmente, a partir del trabajo de Lavandera (1978) donde se cuestionó explícitamente dicha extensión, arguyendo que no estaba garantizado en el estudio de dichas variables el principio de invariabilidad a nivel semántico, imprescindible para la consideración de una variable sociolingüística. Por otra parte, la aplicación del análisis sociolingüístico a la variación morfológica y léxica no ha suscitado un debate tan acalorado como en el caso de la variación sintáctica: "La duda en este último sentido surgió del hecho de que algunas variables, o tenidas por tales en ciertos análisis, conllevaban cambios de

4 En relación con el español hablado en Chile, por ejemplo, algunas variables sintácticas estudiadas son el dequeísmo en Prieto (1995-1996) y la duplicación de clíticos en SilvaCorvalán (2001). 
significación" (López Morales 1990: 83). Por consiguiente, la discusión se ha centrado en determinar si en el estudio de la variación sintáctica se cumple el principio de homogeneidad semántica.

En principio, la variación lingüística "definida como el uso alterno de formas diferentes de decir lo mismo, se puede encontrar prácticamente en todos los niveles de la lengua, desde el más concreto (fonético-fonológico) al más amplio (discurso, por ejemplo), pasando por la gramática y el léxico" (Moreno Fernández 1998: 19). Por ello, la ampliación de los estudios variacionistas al plano discursivo no está descartada de antemano. En relación con el problema que nos ocupa, Cortés (1988) aborda, en particular, la posibilidad de llevar a cabo un estudio cuantitativo de los marcadores del discurso. Al respecto, dicho autor recalca la necesidad de distinguir un estudio cuantitativo - que tan solo describe la variación lingüística en términos de frecuencias de uso de variantes de una misma variable lingüística según factores del contexto extralingüístico- de uno sociolingüístico, en propiedad, que además correlaciona dichas frecuencias dentro de una matriz que explica las causas de esa variación. Según Cortés, pese a las limitaciones que se ha impuesto al estudio variacionista de los marcadores del discurso, la variabilidad de los mismos no está bajo cuestionamiento, ya que:

Toda elección de un marcador, como la de cualquier otro fenómeno fónico, gramatical o léxico, puede venir condicionada bien por una serie de circunstancias estilísticas -registros más o menos formales-, bien por la pertenencia del hablante a un determinado grupo sociocultural -nivel de cultura, edad, sexo-, bien por la modalidad -oral, escrita-, etc. (Cortés 1988: 152).

En efecto, el mismo autor proporciona algunos datos de su propia indagación respecto de los condicionamientos socioculturales que inciden en el uso de o sea que y de modo que o de manera que en el español oral de León; según los cuales o sea que es empleado -mayoritariamente-por hablantes leoneses jóvenes y de menor cultura, mientras que de modo que y de manera que los utilizan sujetos de mayor edad y nivel educacional. Ahora bien, sobre la base de otros estudios cuantitativos de los marcadores y la discusión en torno a la capacidad heurística del concepto de variable sociolingüística, Cortés (1988: 153) se pregunta "¿puede estudiarse el marcador como variable?". A este respecto, basado en Romaine y Winford, Cortés señala que una aproximación cuantitativa a los conectores podría clasificarse dentro de un estudio sociolingüístico "sintáctico puro". Un análisis cuantitativo o sociolingüístico de los marcadores del discurso es posible solo si se logra determinar que dos o más formas de este tipo resultan estar en "distribución complementaria" respecto de los factores sociodemográficos de los 
hablantes. En rigor, entonces, un análisis variacionista de los marcadores es posible en la medida en que se correlacionen dichos factores con formas que cumplen una misma función en el discurso:

Existe la idea, cada vez más aceptada, de que la extensión del análisis variacionista al nivel sintáctico lleva consigo una nueva consideración en cuanto a la equivalencia semántica de las variantes: las variables del discurso se pueden determinar a partir de una función común en el discurso (Cortés 1988: 154).

Por ello, previo al estudio cuantitativo de los marcadores, es necesario que estudios de tipo sintáctico-pragmático identifiquen -precisamente- cuáles son esas funciones pragmáticas compartidas por dos o más formas alternantes en el discurso:

Por consiguiente, antes de afrontar un estudio variacionista sintáctico, el investigador tendrá que saber, a través de los análisis previos cualitativopragmáticos, si se encuentra ante formas que en determinados contextos puedan alternar (Cortés 1988: 155).

Finalmente, Cortés concluye que el estudio variacionista de los marcadores es posible si se cumple el fuerte requisito de contrastar las frecuencias de conectores que cumplan las mismas funciones, lo que trae aparejadas no pocas dificultades en el análisis de estos elementos:

El establecimiento de correlaciones sociolingüísticas válidas deberá hacerse con respecto a cada una de dichas funciones, de los diferentes contextos en los que quedan neutralizadas sus diferencias, etc.; todo lo cual complica la extensión del concepto de variable cuando pretendamos aplicarlo al estudio de los referidos marcadores (Cortés 1988: 160).

Como vemos, es posible, una vez satisfechas las condiciones de rigor, la extensión del concepto de variable sociolingüística al estudio de los marcadores del discurso. Ya en otro lugar (Prieto y San Martín 20022003), hemos evaluado la posibilidad de aplicar el concepto de variable sociolingüística al estudio del discurso referido, que como variable tendría dos valores o variantes generales: "estilo directo" y "estilo indirecto". En el caso de los marcadores del discurso, una aproximación sociolingüística a su empleo requiere de un análisis pragmático-discursivo previo que identifique las funciones desempeñadas por dichas formas y correlacione las frecuencias de uso de marcadores alternantes, respecto de una misma función, con los factores sociodemográficos de los hablantes. Asimismo, a fin de ser "sociolingüístico" y no meramente "cuantitativo", sería necesario 
someter estas frecuencias a las técnicas de análisis variacionista para, de este modo, interpretar estadísticamente los resultados de tal pesquisa. En nuestra opinión, más allá de las limitaciones que plantea Cortés (1988), la aplicación del concepto de variable sociolingüística al estudio de los marcadores del discurso es promisoria, puesto que este tipo de formas parece cumplir con las condiciones propuestas en el marco del variacionismo, es decir, consistir en "formas alternativas de decir lo mismo". Incluso, en virtud de su estatus pragmático, los marcadores que cumplen una misma función satisfarían no solo la condición de ser formas sinónimas, sino que además la de ser variantes pragmáticamente equivalentes; equivalencia tantas veces esgrimida en el estudio de la variación sintáctica. El meollo del problema radica, más bien, en identificar con precisión las funciones discursivas "variables" y sus correspondientes marcadores o "variantes" en una muestra representativa y estratificada de sujetos de una determinada comunidad de habla. Estas intuiciones fueron ya confirmadas en nuestro estudio sobre los reformuladores de distanciamiento en el habla de Santiago de Chile (San Martín 2004-2005).

\section{METODOLOGÍA}

\subsection{CORPUS}

El corpus que sirvió de base para el análisis del presente estudio consistió en 54 entrevistas sociolingüísticas que corresponden a la mitad del corpus de Santiago de Chile en el Proyecto para el Estudio Sociolingüístico del Español de España y América (PRESEEA) ${ }^{5}$. Para la recopilación del corpus sociolingüístico de PRESEEA en Santiago de Chile se aprovechó la instancia de aplicación de un instrumento que, para fines de la investigación sociolingüística del habla de la mencionada ciudad, se realiza anualmente desde 1978 hasta la fecha, en el marco de la asignatura de Sociolingüística que se imparte en las Licenciaturas en Lengua y Literatura Hispánica y Lengua y Literatura Inglesas de la Universidad de Chile ${ }^{6}$. Las entrevistas

\footnotetext{
El equipo de PRESEEA en Santiago de Chile está compuesto por los profesores de la Universidad de Chile, Alfredo Matus y Luis Prieto (coordinadores) y Abelardo San Martín y Silvana Guerrero (asistentes).

6 Dicho instrumento fue implementado por el profesor Dr. Luis Prieto Vera, quien estuvo a cargo de la mencionada asignatura entre 1978 y 2009.
} 
fueron hechas a hombres y mujeres con características socio-demográficas congruentes, aplicando los supuestos metodológicos sugeridos por Labov (1972). Consecuentemente, en dichas situaciones los entrevistadores debían tratar de superar la "paradoja del observador", consiguiendo, de esta forma, una muestra significativa de discurso natural grabado (estilo vernacular) de hablantes representativos de la comunidad de habla en estudio. En las instrucciones a los entrevistadores, se enfatizó que durante la entrevista debía generarse un clima de confianza, a fin de obtener el estilo de habla más espontáneo o natural del sujeto. Asimismo, se les indicó que, idealmente, los hablantes debían olvidarse de que estaban siendo grabados y debían comportarse de modo espontáneo como si estuvieran participando en una conversación natural.

\subsubsection{Población de la muestra}

Para la conformación de la muestra de sujetos entrevistados se consideró la población santiaguina que cumpliera con los siguientes criterios de asignación de hablante nativo de Santiago de Chile: 1) haber nacido y residido en forma ininterrumpida en Santiago; 2) haber residido en forma ininterrumpida en Santiago desde los cinco años de edad, y 3 ) haber nacido en Santiago y haber residido en Santiago la mayor parte de sus vidas, salvo por periodos que sumados no superen los cuatro años en el tramo de 50 años y más y los tres años en el tramo de 35 a 49 años (Prieto 1995-1996: 389398). El cuestionario de la entrevista se aplicó a una muestra de sujetos del tipo denominado "muestra por cuotas", en la que se divide a la población en estratos o categorías y se asigna una cuota a cada uno de los distintos estratos. La muestra así conformada comprende un total de 54 individuos, distribuidos proporcionalmente como se indica en la Tabla 1 que se incluye a continuación.

TABLA 1: Distribución de sujetos de la muestra por nivel educacional, sexo y edad, según PRESEEA

\begin{tabular}{|l|c|c|c|c|c|c|c|}
\hline \multicolumn{7}{|c|}{ Grupo de edad } \\
\cline { 1 - 7 } Nivel educacional & \multicolumn{2}{|c|}{$20-34$} & \multicolumn{2}{c|}{$35-54$} & \multicolumn{2}{c|}{55 y más } & \multirow{2}{*}{ Totales } \\
\cline { 2 - 7 } & $\mathrm{H}$ & $\mathrm{M}$ & $\mathrm{H}$ & $\mathrm{M}$ & $\mathrm{H}$ & $\mathrm{M}$ & \\
\hline Alto & 3 & 3 & 3 & 3 & 3 & 3 & 18 \\
\hline Medio & 3 & 3 & 3 & 3 & 3 & 3 & 18 \\
\hline Bajo & 3 & 3 & 3 & 3 & 3 & 3 & 18 \\
\hline Totales & 9 & 9 & 9 & 9 & 9 & 9 & 54 \\
\hline
\end{tabular}




\subsubsection{Procedimiento de estratificación empleado}

Siguiendo el sistema de estratificación del Proyecto PRESEEA, se estratificó la muestra de sujetos de acuerdo con sus respectivos niveles de instrucción, es decir, según la equivalencia entre los niveles de estudios básico, secundario y superior con los estratos bajo, medio y alto, respectivamente. Sin embargo, con el propósito de garantizar la homogeneidad en la composición de los distintos estratos de la muestra y, por tanto, la representatividad de los mismos en relación con la población analizada, se complementó dicho sistema de estratificación con el procedimiento de estratificación empleado por el proyecto de Estudio Sociolingüístico del Español de Chile (ESECH) ${ }^{7}$, que se basa en el procedimiento sugerido por Prieto (1995-1996). Dicho sistema de estratificación considera una escala de estatus socioeconómico que contempla las siguientes variables independientes: nivel educacional, categoría ocupacional y calidad ambiental de la zona de residencia. Asimismo, para asegurar la rigurosidad de la clasificación socioeconómica de los integrantes de la muestra, se tuvo en cuenta la estratificación social elaborada en 2008 por la Asociación chilena de empresas de Investigación de Mercado (AIM), la descripción básica de grupos socio-económicos realizada por la empresa ICCOM en 2007, así como la información específica proporcionada en 2003 por la empresa ADIMARK. De este modo, se escogieron las entrevistas realizadas a aquellos sujetos que, tras la aplicación de la escala de estratificación social, mostraban lo que Lenski (1954 y 1956) ha denominado cristalización o congruencia de estatus ${ }^{8}$.

En la Tabla 2 se especifican las características socio-demográficas de cada uno de los integrantes de la muestra, clasificados de acuerdo con su nivel educacional, grupo etario y sexo-género.

7 ESECH es un grupo de investigación de la Universidad de Chile al que pertenecen los miembros del Equipo PRESEEA-Santiago.

8 Según Lenski (1954 y 1956), se considera que un individuo es congruente con su estatus cuando las puntuaciones obtenidas en las diferentes dimensiones usadas para medir el estatus, son más o menos iguales, independiente de que sus rangos sean altos, bajos o estén en una extensión media. Cuando las puntuaciones del individuo son muy diferentes, se habla de incongruencia de estatus. 


\section{TABLA 2: Características socio-demográficas} de los integrantes de la muestra

\begin{tabular}{|c|c|c|c|c|c|c|c|c|}
\hline 总 & 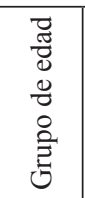 & 离 & $\begin{array}{l}0 \\
800 \\
: 0 \\
0 \\
0\end{array}$ & 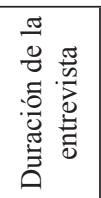 & 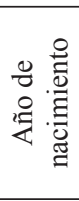 & 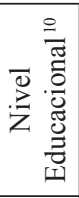 & 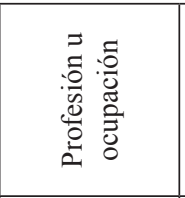 & 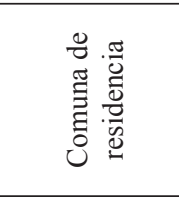 \\
\hline \multirow{18}{*}{ 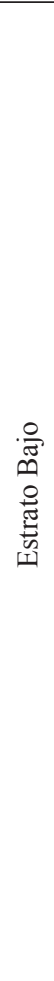 } & \multirow{6}{*}{$\begin{array}{c}20-34 \\
\text { años }\end{array}$} & \multirow{3}{*}{$\mathrm{H}$} & SCHI_H11_001 & $57^{\prime} 40^{\prime \prime}$ & 1983 & BI & $\begin{array}{l}\text { Guardia de } \\
\text { seguridad }\end{array}$ & La Pintana \\
\hline & & & SCHI_H11_002 & $66^{\prime} 43^{\prime \prime}$ & 1984 & MI & \begin{tabular}{|l|}
$\begin{array}{l}\text { Reparador de } \\
\text { computadores }\end{array}$ \\
\end{tabular} & Maipú \\
\hline & & & SCHI_H11_003 & $76^{\prime} 13^{\prime \prime}$ & 1982 & MI & Cesante & El Bosque \\
\hline & & \multirow{3}{*}{ M } & SCHI_M11_007 & $63^{\prime} 53^{\prime \prime}$ & 1977 & BI & Cesante & La Cisterna \\
\hline & & & SCHI_M11_008 & $58^{\prime} 13^{\prime \prime}$ & 1980 & MI & Dueña de casa & El Bosque \\
\hline & & & SCHI_M11_009 & $51^{\prime} 10^{\prime \prime}$ & 1976 & $\mathrm{BC}$ & Dueña de casa & Quinta Normal \\
\hline & \multirow{6}{*}{$\begin{array}{c}35-54 \\
\text { años }\end{array}$} & \multirow{3}{*}{$\mathrm{H}$} & SCHI_H21_013 & $55^{\prime} 54^{\prime \prime}$ & 1966 & MI & \begin{tabular}{|l|}
$\begin{array}{l}\text { Cuidador de } \\
\text { caballos }\end{array}$ \\
\end{tabular} & Independencia \\
\hline & & & SCHI_H21_014 & $61 ’ 37$ & 1961 & BI & Yesero & Cerro Navia \\
\hline & & & SCHI_H21_015 & $46^{\prime} 06^{\prime \prime}$ & 1951 & MI & \begin{tabular}{|l|}
$\begin{array}{l}\text { Transportista } \\
\text { escolar }\end{array}$ \\
\end{tabular} & La Florida \\
\hline & & \multirow{3}{*}{ M } & SCHI_M21_019 & $60 ' 53 "$ & 1959 & BI & Comerciante & La Pintana \\
\hline & & & SCHI_M21_020 & $57^{\prime} 56^{\prime \prime}$ & 1969 & MI & $\begin{array}{l}\text { Auxiliar de } \\
\text { aseo }\end{array}$ & \begin{tabular}{|l|} 
Estación \\
Central
\end{tabular} \\
\hline & & & SCHI_M21_021 & $55^{\prime} 57$ & 1961 & BI & Niñera & Puente Alto \\
\hline & \multirow{6}{*}{$\begin{array}{l}55 \text { y } \\
\text { más } \\
\text { años }\end{array}$} & \multirow{3}{*}{$\mathrm{H}$} & SCHI_H31_025 & $70^{\prime} 16^{\prime \prime}$ & 1918 & $\mathrm{BI}$ & Jubilado & Recoleta \\
\hline & & & SCHI_H31_026 & 56’09" & 1937 & $\mathrm{BC}$ & Albañil & Santiago \\
\hline & & & SCHI_H31_027 & $54^{\prime} 45^{\prime \prime}$ & 1954 & $\mathrm{BI}$ & Obrero & San Bernardo \\
\hline & & \multirow{3}{*}{ M } & SCHI_M31_031 & $50 \prime 16 "$ & 1936 & $\mathrm{BI}$ & Dueña de casa & San Ramón \\
\hline & & & SCHI_M31_032 & $62 " 17 "$ & 1930 & $\mathrm{BI}$ & Dueña de casa & San Bernardo \\
\hline & & & SCHI_M31_033 & $51^{\prime} 58^{\prime \prime}$ & 1951 & BI & Dueña de casa & Conchalí \\
\hline
\end{tabular}

9 El código de los sujetos tiene las siguientes equivalencias: SCHI: Santiago de Chile; $\mathrm{Sexo}=\mathrm{H}$ (hombre) y $\mathrm{M}$ (mujer). El primer número que le sigue a dichas equivalencias corresponde al código del grupo de edad: $1=20$ a 34 años, $2=35$ a 54 años y $3=55$ años y más; el segundo número corresponde al nivel educacional: $1=$ Bajo (sin estudios o con instrucción primaria o instrucción secundaria incompleta), $2=$ Medio (con instrucción secundaria) y $3=$ Alto (con instrucción superior). Los dígitos finales corresponden a numeración correlativa que se le asignó a los sujetos en el corpus PRESEEA Santiago de Chile.

10 Las siglas de esta columna tienen las siguientes equivalencias: $\mathrm{UC}=$ educación universitaria completa; $\mathrm{UI}=$ educación universitaria incompleta; TPC $=$ educación técnicaprofesional completa; TPI = educación técnica-profesional incompleta; $\mathrm{MC}=$ educación media completa; $\mathrm{MI}=$ educación media incompleta; $\mathrm{BC}=$ educación básica completa; $\mathrm{BI}=$ educación básica incompleta. 
Continuación de la tabla 2

\begin{tabular}{|c|c|c|c|c|c|c|c|c|}
\hline 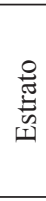 & 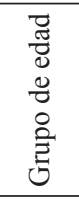 & 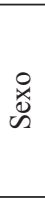 & $\begin{array}{l}80.00 \\
: 7 \\
: 0 \\
0 \\
0\end{array}$ & 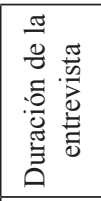 & 兽 & 离 & 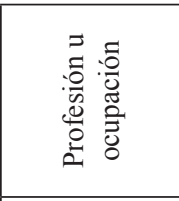 & 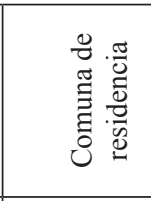 \\
\hline \multirow{18}{*}{ 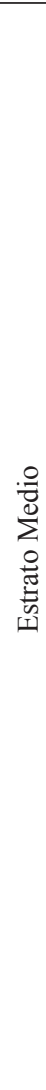 } & \multirow{6}{*}{$\begin{array}{c}20-34 \\
\text { años }\end{array}$} & \multirow{3}{*}{$\mathrm{H}$} & SCHI_H12_037 & $71 " 17 "$ & 1979 & $\mathrm{MC}$ & Chofer & Puente alto \\
\hline & & & SCHI_H12_038 & $67^{\prime} 07^{\prime \prime}$ & 1986 & $\mathrm{MC}$ & $\begin{array}{l}\text { Empleado en } \\
\text { imprenta }\end{array}$ & Peñalolén \\
\hline & & & SCHI_H12_039 & $55^{\prime} 57^{\prime \prime}$ & 1983 & $\mathrm{MC}$ & $\begin{array}{l}\text { Operario en } \\
\text { Fotocopiadora }\end{array}$ & $\begin{array}{l}\text { Estación } \\
\text { Central }\end{array}$ \\
\hline & & \multirow{3}{*}{ M } & SCHI_M12_043 & $56^{\prime} 43^{\prime \prime}$ & 1988 & $\mathrm{MC}$ & Cesante & La Granja \\
\hline & & & SCHI_M12_044 & $66^{\prime} 58^{\prime \prime}$ & 1976 & $\mathrm{MC}$ & $\begin{array}{l}\text { Empleada en } \\
\text { lavandería }\end{array}$ & La Cisterna \\
\hline & & & SCHI_M12_045 & $59^{\prime} 40^{\prime \prime}$ & 1984 & TPC & $\begin{array}{l}\text { Técnico } \\
\text { paramédico }\end{array}$ & Santiago \\
\hline & \multirow{6}{*}{$\begin{array}{c}35-54 \\
\text { años }\end{array}$} & \multirow{3}{*}{$\mathrm{H}$} & SCHI_H22_049 & $74 " 34 "$ & 1963 & $\mathrm{MC}$ & Chofer & Maipú \\
\hline & & & SCHI_H22_050 & $55^{\prime} 15^{\prime \prime}$ & 1964 & $\mathrm{MC}$ & $\begin{array}{l}\text { Administrador } \\
\text { de restaurante }\end{array}$ & La Florida \\
\hline & & & SCHI_H22_051 & $59^{\prime} 15^{\prime \prime}$ & 1960 & $\mathrm{MC}$ & Taxista & Macul \\
\hline & & \multirow{3}{*}{ M } & SCHI_M22_055 & $69^{\prime} 48^{\prime \prime}$ & 1963 & $\mathrm{MC}$ & Dueña de casa & Maipú \\
\hline & & & SCHI_M22_056 & $61^{\prime} 37^{\prime \prime}$ & 1962 & ТPC & Dueña de casa & Pudahuel \\
\hline & & & SCHI_M22_057 & $50^{\prime} 10^{\prime \prime}$ & 1957 & $\mathrm{MC}$ & Dueña de casa & Macul \\
\hline & \multirow{6}{*}{$\begin{array}{l}55 \text { y } \\
\text { más } \\
\text { años }\end{array}$} & \multirow{3}{*}{$\mathrm{H}$} & SCHI_H32_061 & 73 '09" & 1929 & TPC & Jubilado & San Joaquín \\
\hline & & & SCHI_H32_062 & $50 ' 43^{\prime \prime}$ & 1946 & $\mathrm{MC}$ & Dueño de casa & $\begin{array}{l}\text { Estación } \\
\text { Central }\end{array}$ \\
\hline & & & SCHI_H32_063 & $54^{\prime} 33^{\prime \prime}$ & 1944 & $\mathrm{MC}$ & Relojero & Santiago \\
\hline & & \multirow{3}{*}{ M } & SCHI_M32_067 & $86^{\prime} 25^{\prime \prime}$ & 1946 & $\mathrm{MC}$ & $\begin{array}{l}\text { Auxiliar de } \\
\text { enfermos }\end{array}$ & San Miguel \\
\hline & & & SCHI_M32_068 & $50^{\prime} 51^{\prime \prime}$ & 1945 & $\mathrm{MC}$ & Dueña de casa & Macul \\
\hline & & & SCHI_M32_069 & $48^{\prime} 37^{\prime \prime}$ & 1933 & MI & Jubilada & Puente Alto \\
\hline
\end{tabular}


Continuación de la tabla 2

\begin{tabular}{|c|c|c|c|c|c|c|c|c|}
\hline 胥 & 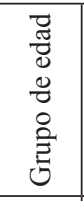 & 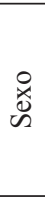 & $\begin{array}{l}8 \\
.00 \\
: 0 \\
0 \\
0\end{array}$ & 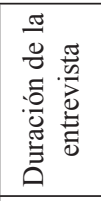 & 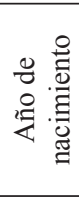 & 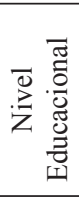 & 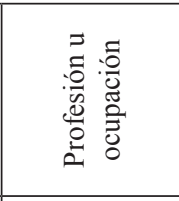 & 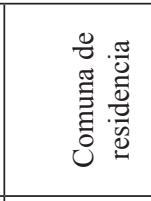 \\
\hline \multirow{18}{*}{ 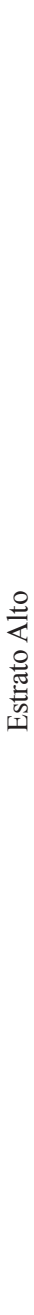 } & \multirow{6}{*}{$\begin{array}{c}20-34 \\
\text { años }\end{array}$} & \multirow{3}{*}{$\mathrm{H}$} & SCHI_H13_073 & $59^{\prime} 00^{\prime \prime}$ & 1983 & UI & $\begin{array}{l}\text { Constructor } \\
\text { civil }\end{array}$ & Providencia \\
\hline & & & SCHI_H13_074 & $52^{\prime} 06^{\prime \prime}$ & 1985 & UI & $\begin{array}{l}\text { Estudiante } \\
\text { diseño } \\
\text { industrial }\end{array}$ & Providencia \\
\hline & & & SCHI_H13_075 & $51 ' 49^{\prime \prime}$ & 1986 & UI & $\begin{array}{l}\text { Estudiante de } \\
\text { sonido }\end{array}$ & Santiago \\
\hline & & \multirow{3}{*}{ M } & SCHI_M13_079 & 71'38" & 1980 & UI & $\begin{array}{l}\text { Estudiante } \\
\text { Licenciatura } \\
\text { Inglesa }\end{array}$ & Santiago \\
\hline & & & SCHI_M13_080 & $51^{\prime} 45^{\prime \prime}$ & 1985 & UC & $\begin{array}{l}\text { Traductora e } \\
\text { intérprete en } \\
\text { inglés }\end{array}$ & Ñuñoa \\
\hline & & & SCHI_M13_081 & $50 ’ 22 ”$ & 1977 & $\mathrm{UC}$ & Psicóloga & Ñuñoa \\
\hline & \multirow{6}{*}{$\begin{array}{c}35-54 \\
\text { años }\end{array}$} & \multirow{3}{*}{$\mathrm{H}$} & SCHI_H23_085 & $52 ' 58^{\prime \prime}$ & 1964 & UC & $\begin{array}{l}\text { Químico } \\
\text { farmacéutico }\end{array}$ & Peñalolén \\
\hline & & & SCHI_H23_086 & $50 ’ 02 ”$ & 1958 & UC & $\begin{array}{l}\text { Director de } \\
\text { colegio }\end{array}$ & La Cisterna \\
\hline & & & SCHI_H23_087 & $57^{\prime} 26 "$ & 1964 & $\mathrm{UC}$ & $\begin{array}{l}\text { Director de } \\
\text { orquesta y } \\
\text { productor } \\
\text { musical } \\
\end{array}$ & Macul \\
\hline & & \multirow{3}{*}{ M } & SCHI_M23_091 & $57^{\prime} 37^{\prime \prime}$ & 1973 & UC & Abogado & Providencia \\
\hline & & & SCHI_M23_092 & $62 ' 54^{\prime \prime}$ & 1956 & UC & Nutricionista & Ñuñoa \\
\hline & & & SCHI_M23_093 & $63^{\prime} 55^{\prime \prime}$ & 1960 & UI & $\begin{array}{l}\text { Decoradora de } \\
\text { interiores }\end{array}$ & Ñuñoa \\
\hline & \multirow{6}{*}{$\begin{array}{l}55 \text { y } \\
\text { más } \\
\text { años }\end{array}$} & \multirow{3}{*}{$\mathrm{H}$} & SCHI_H33_097 & $60{ }^{\prime} 41^{\prime \prime}$ & 1937 & UI & $\begin{array}{l}\text { Profesor de } \\
\text { aviación }\end{array}$ & Macul \\
\hline & & & SCHI_H33_098 & $46^{\prime} 57^{\prime \prime}$ & 1952 & $\mathrm{UC}$ & $\begin{array}{l}\text { Ingeniero } \\
\text { comercial }\end{array}$ & Ñuñoa \\
\hline & & & SCHI_H33_099 & $55^{\prime} 11^{\prime \prime}$ & 1947 & $\mathrm{UC}$ & Químico & Ñuñoa \\
\hline & & \multirow{3}{*}{ M } & SCHI_M33_103 & $64^{\prime} 18^{\prime \prime}$ & 1931 & UC & Psiquiatra & Vitacura \\
\hline & & & SCHI_M33_104 & $60 ’ 37^{\prime \prime}$ & 1952 & $\mathrm{UC}$ & Médico & Providencia \\
\hline & & & SCHI_M33_105 & $55^{\prime} 45^{\prime \prime}$ & 1947 & UC & Kinesióloga & Santiago \\
\hline
\end{tabular}




\section{PRESENTACIÓN Y ANÁLISIS DE LOS RESULTADOS}

En nuestro corpus se identificó un total de 1007 casos en los que se empleó la función "marcador interrogativo de control de contacto". Para el cumplimiento de esta última función se identificaron, a su vez, 12 partículas: ¿cachái?, ¿ya?, ¿a?, ¿no?, ¿me entiendes?, ¿no cierto?, ¿entiendes(di)?, ¿cierto?, ¿viste?, ¿te has fijado?, ¿tefijas? y ¿sí ${ }^{11}$ En el Gráfico 1 se muestra el porcentaje de frecuencia de los marcadores interrogativos de control de contacto en el corpus, entre los que destaca - por mucho- el empleo del marcador ¿cachái? con un $86,7 \%$ de las preferencias, correspondiente a 874 casos. Le siguen en importancia las partículas ¿ya? (44 casos, 4,4\%), ¿a? (26 ocurrencias, 2,6\%), ¿no? (25 casos, 2,5\%), ¿me entiendes? (11 ocurrencias, $1,1 \%)$ y ¿no cierto? (10 casos, $1 \%)$. El resto de los marcadores relevados con la función "marcador interrogativo de control de contacto", es decir, ¿entiendes(di)?, ¿cierto?, ¿viste?, ¿te has fijado?, ¿te fijas? y ¿si? tiene una ocurrencia significativamente menor, inferior incluso al $1 \%$ (esto es, bajo las 10 ocurrencias). No obstante la claridad de las tendencias que puede desprenderse de estos datos estadísticos, cabe destacar el carácter preliminar y no definitivo de estas cifras, ya que solo se trata de la mitad del Corpus PRESEEA de Santiago de Chile.

11 En la conformación del inventario de marcadores interrogativos de control de contacto registrados en nuestros materiales, hemos optado por ceñirnos a las formas efectivamente relevadas. En concordancia con ello, el marcador ¿cachái? solo se registró en su forma voseante con elisión de /-s/ final; en cambio, ¿entiendes(dí)? se relevó tanto en su forma voseante como no voseante con y $\sin /-\mathrm{s} /$, de ahí el uso de los paréntesis. 
Gráfico 1: Porcentaje de frecuencia de los marcadores interrogativos de control de contacto en el corpus PRESEEA-SA

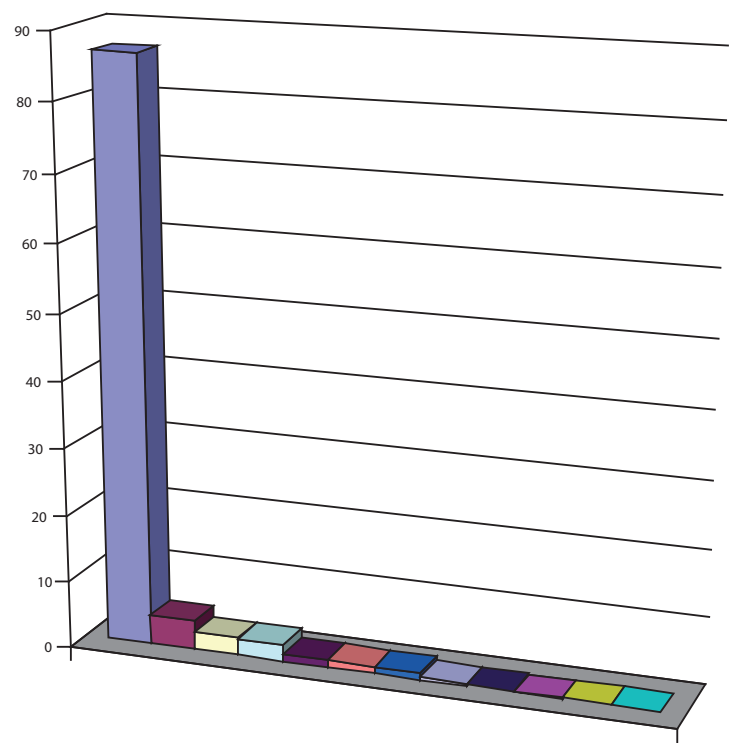

\begin{tabular}{|l|r|}
\hline$\square_{\text {¿cachai? }}$ & 86,7 \\
\hline$\square_{\text {¿ya? }}$ & 4,4 \\
\hline$\square_{\text {¿a? }}$ & 2,6 \\
\hline$\square_{\text {¿no? }}$ & 2,5 \\
\hline $\mathbf{\square}_{\text {¿me entiendes? }}$ & 1,1 \\
\hline$\square_{\text {¿no cierto? }}$ & 1 \\
\hline $\mathbf{\square}_{\text {¿entiendes(dí)? }}$ & 0,9 \\
\hline$\square_{\text {¿cierto? }}$ & 0,3 \\
\hline $\mathbf{\square}_{\text {¿viste? }}$ & 0,2 \\
\hline $\mathbf{\square}_{\text {¿te has fijado? }}$ & 0,1 \\
\hline$\square_{\text {¿te fijas? }}$ & 0,1 \\
\hline $\mathbf{\square}_{\text {¿sí? }}$ & 0,1 \\
\hline
\end{tabular}


En general, se trata de partículas cuya función fática ha sido ya reconocida en otras variedades del español, derivada del significado primigenio de verbos de comprensión como entender, de percepción como ver y fijarse, o de adverbios de negación, afirmación o certeza. Tanto la baja ocurrencia de empleo de ¿no?, como la insignificante presencia de $j s i ́$ ? y la inexistencia de $¿ e$ ? contrastan con el empleo de los marcadores fáticos documentado en otras comunidades, en especial, con el de las variedades peninsulares. De igual modo, el marcador interrogativo de control de contacto más frecuente, ¿cachái?, corresponde a la forma voseante de la segunda persona del singular del verbo cachar, unidad léxica de gran frecuencia en el español de Chile actual -en especial entre los sujetos más jóvenes- y que ha adquirido múltiples valores semánticos y pragmáticos (Urzúa-Carmona 2006). El verbo cachar y sus derivados se han transformado en una de las características diferenciales del español hablado en Chile y ha llamado la atención no solo de los especialistas, sino que también de los hablantes extranjeros. En general, existe acuerdo en señalar el origen inglés del verbo cachar "sospechar, entender, comprender", derivándolo del inglés to catch "agarrar", por lo que se trataría de un anglicismo (DRAE, s. v. cachar) ${ }^{12}$. En su estudio sobre el verbo cachar en el español de Chile, Urzúa-Carmona (2006) incluye ya su función fática, mediante la cual "el emisor se asegura de que su mensaje está siendo entendido por el receptor" (2006: 104-105). Por su parte, el DUECH (s. v. cachar(1)) destaca su carácter espontáneo y recoge las siguientes acepciones: 1. Percibir con la visión o los oídos; 2 . Conocer, tener conocimiento; 3 . Entender, comprender y 4. Suponer, creer. Asimismo, registra su empleo como marcador del discurso juvenil: "Especialmente entre los jóvenes, se usa para comprobar que se tiene la atención del interlocutor durante una narración o conversación [...]" (DUECH, s. v. ¿cachái?). El DA (s. v. cachar(se)), por otro lado, registra la locución juvenil chilena ¿cachái o no?, la que "se usa par dar por supuesta la ratificación tácita del interlocutor sobre aquello de lo que se está hablando".

En los ejemplos 1 a 5 puede apreciarse el funcionamiento de algunos de los marcadores interrogativos de control de contacto relevados en el corpus:

1. E: hacer carrete piola en la casa/ un asa[d]o -I: sí po/ su asa[d]o ¿cachái?/ pero máh así como otra onda/no/ ¿cachái?/ porque salí/ igual/ salí cuando tení plata no máh po/ pero a veceh no hay lah posibilidadeh de salir/ no todoh loh amigoh po ¿cachái?/ o sea que esah fecha// suben to[d] oh loh precioh po hue[v]ón/ a veceh doh lucah un anticucho hue[v]ón/

12 Para mayor detalle sobre el origen etimológico y las funciones semánticas y pragmáticas del verbo cachar puede consultarse el trabajo de Urzúa-Carmona (2006). 
puta hue[v]ón te comí doh anticucho y quedái con el diente así y quedái sin plata po hue[v]ón -E: Sí po hue[v]ón/ no alcanzái ni a tomarte una chichita po hue[v]ón -I: No po ¿cachái?/ [en]tonceh/no/ igual es buena esa fiesta ¿cachái? Pero/ es como normal al final po ¿cachái?/ siempre hací como un asa[d]o/ vái a visitar gente ¿cachái?/ pero así un carrete así como ir pa[ra] fonda/ no (SCHI H12 039).

2. E.: oye hue[v]ón/ ¿y tu teníh un grupo de amigoh con loh que salíh/ carreteai? -I: aa/ si carreteo con voh poh hue[v]ón/ ¿cachái?/ carreteo/ puta/ salgo con purah personah universitariah/ igual/ igual tengo $\mathrm{mi} / \mathrm{mi}$ grupo así como/ el/ el/ el carrete flaite/ ¿cachái?/ como/ vamoh a puro tomar/ y puro/ a puro poncear// pero/ me guhta máh ehtar con uhtedeh/ que con loh otro/ porque/ puta/ tenimoh horarioh losotroh pa[ra] carretear/ como el lobby/ tomí/ tomar/ ¿cachái?/ conversar/ tirar la talla/ aprender un poquito máh del mundo/ yy/ yo aprendo harto igual/ ¿cachái?/ y hahta que eh momento que tenimoh que bailar/ "pongámonoh a bailar/ hue[v]iemoh" ya/ hue[v]iamoh/ llegó la mañana/ y seguimoh hue[v] iando/ ¿cachái?/ almorz// tomamoh desayuno hue[v]ón/ loh vinimoh a la casa tuya/ yy/ hahta el almuerzo poh hue[v]ón/ ¿cachái?/ esoh son mih amigoh (SCHI H11 001).

3. E: claro/ porque era como una lista a la que se fueron sumando -I: se han i[d]o sumando sumando/ en ehte momento no me acuerdo cuántah son/ pero como sesenta una cosa así/ ¿ya?/ pero// tú comprenderah que sesenta patologíah aunque ehtá sí/ ehtán// como/ lah máh importanteh/ ¿ya?/ pero hay cientoh y cientoh de enfermeda[d]eh poh -E: seguro (SCHI M33 104).

4. E: ¿y te da mucho miedo al darte cuenta // de que tú le buhcah explicacioneh / y no la hay? -I: a esoh ruidoh/a esa sensación/y te da un miedo/ tremendo/ cuando te dah cuenta que no hay explicación para lo que estáh sintiendo y para lo que tú estáh ehcuchando -E: mm/ ya -I: y a travéh del tiempo tú/ ya son tan repetitivas lo/ la sensación a veceh loh ruidoh que te dah cuenta que son situacioneh paranormaleh ¿entendih? (SCHI M11 008).

5. E.: ¿ha tenido alguna veh un sueño premonitorio/ o sea/ que haya soña[d] o con algo que después se le cumpla? -I.: a ver// sueño sueño ee tanto como / uy no ve como soñarlo a ver me va a dihculpar/ sí tengo ten/ o sea no sé/ no sé cómo ehplicarlo/ pero tengo algo yo de que si yo// sueño con guagua// por eso me dijo algo que me que me sucede -E.: aha I.: despuéh ¿no cierto? ya/ si yo a uhted le sueño con guaguah eh pero sagrado que yo tenga una dihcusión en mi hogar// pero de que tengo ya hablemoh/ no uso de razón sino que de que estoy en mi hogar/ o sea/ dehde que me casé hahta el día de hoy -E.: ya (SCHI M32 067). 
Como puede apreciarse en 1-5, las partículas que hemos destacado en cursiva corresponden a nuestra definición de marcadores interrogativos de control de contacto, ya que por su intermedio el hablante cautela la recepción e interpretación eficiente de su mensaje por parte del interlocutor. Se ha discutido bastante sobre el supuesto carácter expletivo (innecesario) de algunas de estas muletillas que proliferan en el discurso conversacional. Sin embargo, concordamos con Briz (2001) y Portolés (2001) en que más allá del empleo reiterado como el que se recoge en 1 y 2: "nada redundante, nada expletivo es el valor de [los] conectores [...] que de forma reiterada aparecen como hilos tensores, nudos continuativos en el habla [...]" (Briz 2001: 203-204), ya que estas unidades: "poseen un valor para el buen funcionamiento de la conversación, no se pueden considerar innecesarios, ya que no dejan de utilizarse con un cierto cometido en el proceso de la interacción verbal" (Portolés 2001: 133-134). Los marcadores ejemplificados en 1-5, colaboran para hacer progresar la conversación de modo eficiente. Incluso el abundante empleo de ¿cachái? en 1 y 2 puede ser interpretado como un indicador de que el hablante intenta ser colaborativo en el intercambio, reforzando el contacto y controlando la comprensión de su interlocutor en el coloquio. Finalmente, cabe destacar que el empleo de ¿cachái? en hablantes jóvenes, como el que se ilustra en 1 y 2 , evidentemente está motivado por un factor de identidad grupal; aspecto que quedará explicado de modo más claro, más abajo, con el Gráfico 3.

Por otro lado, por lo que se refiere al empleo de los marcadores de control de contacto interrogativos y el nivel educacional de los sujetos que conforman la muestra bajo análisis, en la Tabla 3 y el Gráfico 2, se ilustra la correlación entre dichas variables:

Tabla 3: Número y porcentaje de frecuencia de marcadores de control de contacto interrogativos según nivel educacional

\begin{tabular}{|c|c|c|c|c|}
\hline \multirow[b]{2}{*}{ Marcador } & \multicolumn{3}{|c|}{ Nivel educacional } & \multirow[b]{2}{*}{ Total } \\
\hline & Bajo & Medio & Alto & \\
\hline ¿cachái? & $409(40,7 \%)$ & $190(18,7 \%)$ & $275(27,3 \%)$ & $874(86,7 \%)$ \\
\hline ¿уa? & $0(0 \%)$ & $0(0 \%)$ & $44(4,4 \%)$ & $44(4,4 \%)$ \\
\hline ¿a? & $10(1 \%)$ & $0(0 \%)$ & $16(1,6 \%)$ & $26(2,6 \%)$ \\
\hline ¿no? & $0(0 \%)$ & $2(0,2 \%)$ & $23(2,3 \%)$ & $25(2,5 \%)$ \\
\hline ¿me entiendes? & $3(0,3 \%)$ & $8(0,8 \%)$ & $0(0 \%)$ & $11(1,1 \%)$ \\
\hline ¿no cierto? & $0(0 \%)$ & $4(0,4 \%)$ & $6(0,6 \%)$ & $10(1 \%)$ \\
\hline ¿entiendes(dí)? & $2(0,2 \%)$ & $2(0,2 \%)$ & $5(0,5 \%)$ & $9(0,9 \%)$ \\
\hline ¿cierto? & $0(0 \%)$ & $2(0,2 \%)$ & $1(0,1 \%)$ & $3(0,3 \%)$ \\
\hline
\end{tabular}




\begin{tabular}{|l|l|l|l|l|}
\hline ¿viste? & $2(0,2 \%)$ & $0(0 \%)$ & $0(0 \%)$ & $2(0,2 \%)$ \\
\hline ¿te has fijado? & $1(0,1 \%)$ & $0(0 \%)$ & $0(0 \%)$ & $1(0,1 \%)$ \\
\hline ¿te fijas? & $0(0 \%)$ & $0(0 \%)$ & $1(0,1 \%)$ & $1(0,1 \%)$ \\
\hline ¿sí? & $0(0 \%)$ & $0(0 \%)$ & $1(0,1 \%)$ & $1(0,1 \%)$ \\
\hline Total & $427(42,5 \%)$ & $208(20,5 \%)$ & $372(37 \%)$ & $1007(100 \%)$ \\
\hline
\end{tabular}

Gráfico 2: Porcentaje de frecuencia de los marcadores interrogativos de control de contacto según nivel educacional

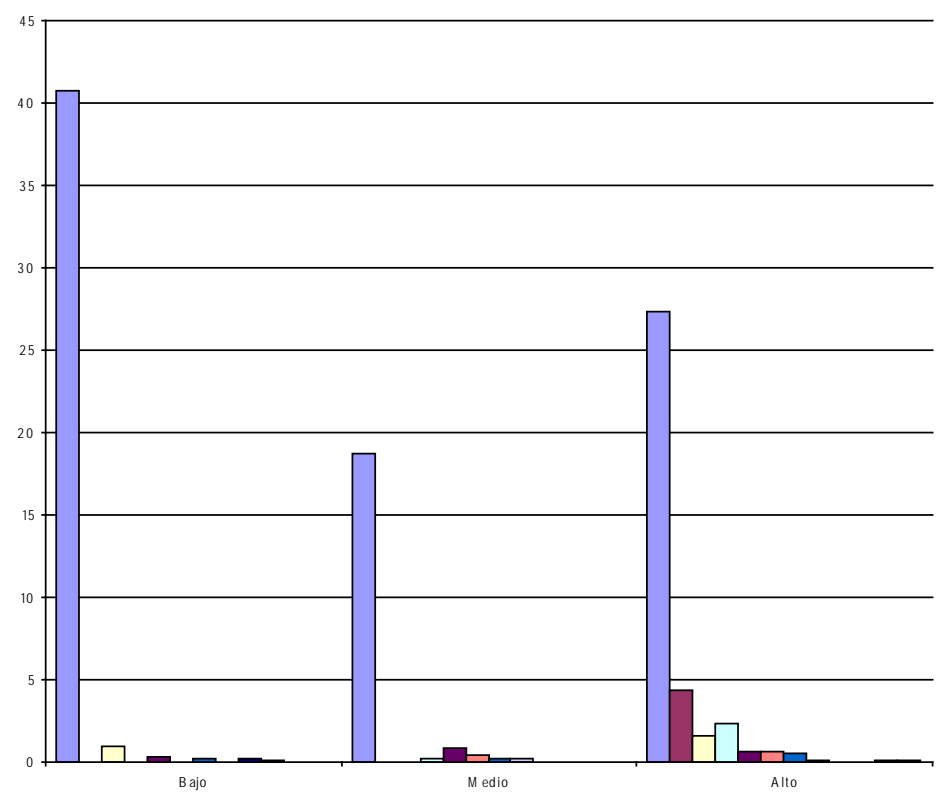

\begin{tabular}{|l|r|r|r|}
\hline & Bajo & Medio & Alto \\
\hline$\square_{\text {¿cachai? }}$ & 40,7 & 18,7 & 27,3 \\
\hline$\square_{\text {¿ya? }}$ & 0 & 0 & 4,4 \\
\hline$\square_{\text {¿a? }}$ & 1 & 0 & 1,6 \\
\hline$\square_{\text {¿no? }}$ & 0 & 0,2 & 2,3 \\
\hline$\square_{\text {¿me entiendes? }}$ & 0,3 & 0,8 & 0,6 \\
\hline$\square_{\text {¿no cierto? }}$ & 0 & 0,4 & 0,6 \\
\hline$\square_{\text {¿entiendes(dí)? }}$ & 0,2 & 0,2 & 0,5 \\
\hline$\square_{\text {¿cierto? }}$ & 0 & 0,2 & 0,1 \\
\hline$\square_{\text {¿viste} ?}$ & 0,2 & 0 & 0 \\
\hline $\mathbf{\square}_{\text {¿te has fijado? }}$ & 0,1 & 0 & 0,1 \\
\hline$\square_{\text {¿te fijas? }}$ & 0 & 0 & 0,1 \\
\hline $\mathbf{\square}_{\text {¿sí? }}$ & 0 & 0 & \\
\hline
\end{tabular}


De los datos precedentes podemos concluir que el marcador ¿cachái? muestra un patrón curvilíneo en forma de "u", ya que su empleo, si bien está presente en los tres niveles educacionales, es preferente en los extremos de la escala, esto es, en los niveles bajo y alto del espectro educacional. Asimismo, se observa que la frecuencia de uso del resto de los marcadores interrogativos de control de contacto se concentra en el nivel educacional alto, en donde se verifica una mayor variedad de partículas que cumplen la función discursiva en estudio como ¿ya?, ¿a?, ¿no?, ¿me entiendes? y ¿no cierto?

Por otro lado, en la Tabla 4 y el Gráfico 3, se muestra la correlación entre el empleo de los marcadores interrogativos de control de contacto y el grupo de edad de los sujetos, esto es, la variable etaria en estudio:

Tabla 4: Número y porcentaje de frecuencia de marcadores de control de contacto interrogativos según grupo de edad

Grupo de edad

\begin{tabular}{|c|c|c|c|c|}
\hline Marcador & I (20-34) & II (35-54) & III (55 y más) & Total \\
\hline ¿cachái? & $819(81,5 \%)$ & $55(5,2 \%)$ & $0(0 \%)$ & $874(86,7 \%)$ \\
\hline ¿уy? & $0(0 \%)$ & $0(0 \%)$ & $44(4,4 \%)$ & $44(4,4 \%)$ \\
\hline ¿a? & $0(0 \%)$ & $0(0 \%)$ & $26(2,6 \%)$ & $26(2,6 \%)$ \\
\hline ¿no? & $1(0,1 \%)$ & $0(0 \%)$ & $24(2,4 \%)$ & $25(2,5 \%)$ \\
\hline ¿me entiendes? & $3(0,3 \%)$ & $6(0,6 \%)$ & $2(0,2 \%)$ & $11(1,1 \%)$ \\
\hline ¿no cierto? & $0(0 \%)$ & $6(0,6 \%)$ & $4(0,4 \%)$ & $10(1 \%)$ \\
\hline ¿entiendes(dí)? & $2(0,2 \%)$ & $1(0,1 \%)$ & $6(0,6 \%)$ & $9(0,9 \%)$ \\
\hline ¿cierto? & $1(0,1 \%)$ & $1(0,1 \%)$ & $1(0,1 \%)$ & $3(0,3 \%)$ \\
\hline ¿viste? & $0(0 \%)$ & $2(0,2 \%)$ & $0(0 \%)$ & $2(0,2 \%)$ \\
\hline ¿te has fijado? & $0(0 \%)$ & $1(0,1 \%)$ & $0(0 \%)$ & $1(0,1 \%)$ \\
\hline ¿te fijas? & $0(0 \%)$ & $1(0,1 \%)$ & $0(0 \%)$ & $1(0,1 \%)$ \\
\hline ¿sí? & $0(0 \%)$ & $0(0 \%)$ & $1(0,1 \%)$ & $1(0,1 \%)$ \\
\hline Total & $826(82,2 \%)$ & $73(7 \%)$ & $108(10,8 \%)$ & $1007(100 \%)$ \\
\hline
\end{tabular}


Gráfico 3: Porcentaje de frecuencia de los marcadores interrogativos de control de contacto según grupo de edad

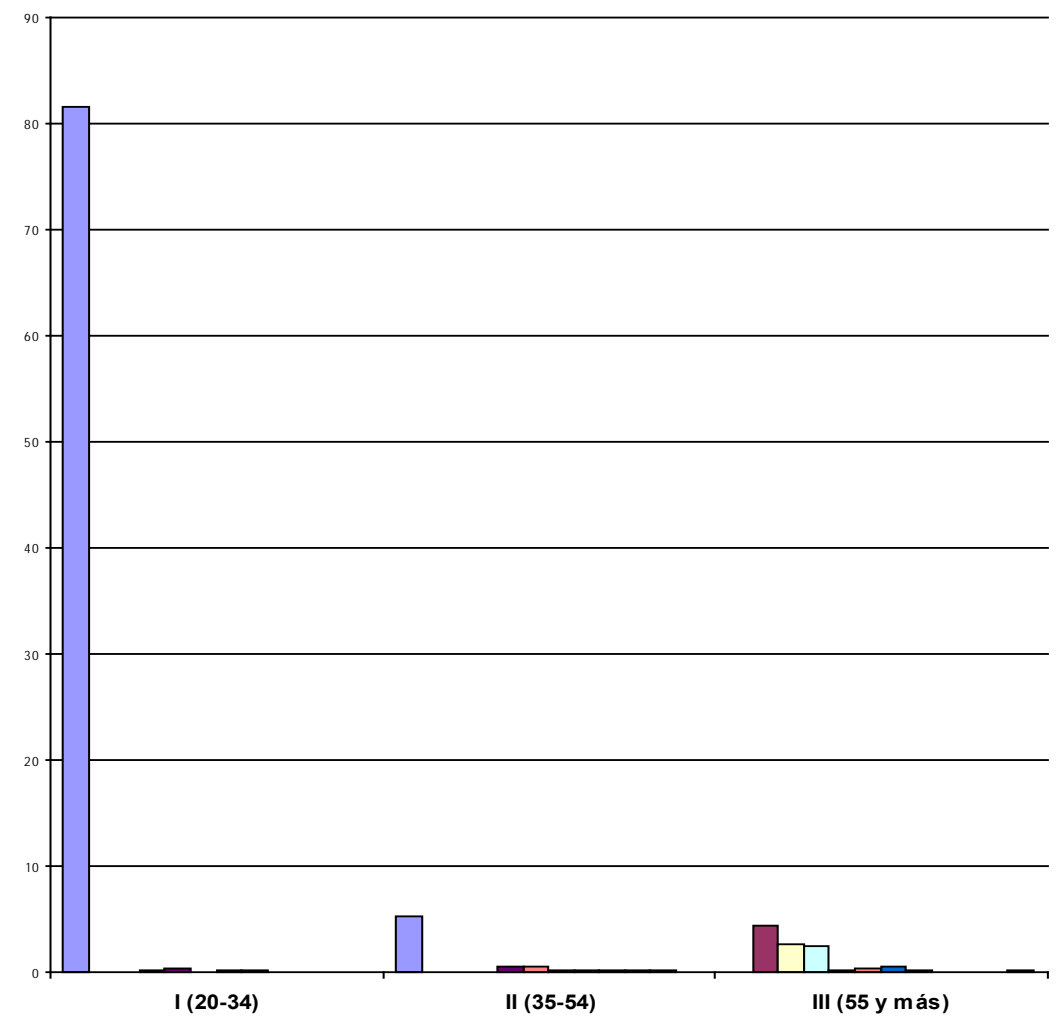

\begin{tabular}{|l|c|c|c|}
\hline & Bajo & Medio & Alto \\
\hline$\square_{\text {¿cachai? }}$ & 81,5 & 5,2 & 0 \\
\hline$\square_{\text {¿ya? }}$ & 0 & 0 & 4,4 \\
\hline$\square_{\text {¿a? }}$ & 0 & 0 & 2,6 \\
\hline$\square_{\text {¿no? }}$ & 0,1 & 0 & 2,4 \\
\hline$\square_{\text {¿me entiendes? }}$ & 0,3 & 0,6 & 0,2 \\
\hline$\square_{\text {¿no cierto? }}$ & 0 & 0,6 & 0,4 \\
\hline$\square_{\text {¿entiendes(dí)? }}$ & 0,2 & 0,1 & 0,6 \\
\hline$\square_{\text {¿cierto? }}$ & 0,1 & 0,1 & 0,1 \\
\hline$\square_{\text {¿viste? }}$ & 0 & 0,2 & 0 \\
\hline$\square_{\text {ite has fijado? }}$ & 0 & 0,1 & 0 \\
\hline$\square_{\text {¿te fijas? }}$ & 0 & 0,1 & 0,1 \\
\hline$\square_{\text {¿sí? }}$ & 0 & 0 & \\
\hline
\end{tabular}


Como es evidente en los datos previamente presentados, el factor etario de los sujetos es el que resulta más sensible al empleo de los marcadores interrogativos de control de contacto. En este sentido, el marcador interrogativo de control de contacto ¿cachái? resulta ser definitivamente juvenil, destacándose el hecho de no haber hallado ningún caso de empleo de dicha partícula por parte de sujetos del grupo de edad igual o superior a 55 años. En dicho grupo, además, se concentra la mayor parte del uso del resto de los marcadores interrogativos de control de contacto, entre los que destacan ¿ya?, ¿a? y ¿no?

Por último, la Tabla 5 y el Gráfico 4 muestran las correlaciones entre el empleo de los marcadores interrogativos de control de contacto y el sexogénero de los sujetos que conforman la muestra de nuestro estudio:

Tabla 5: Número y porcentaje de frecuencia de marcadores de control de contacto interrogativos según sexo-género

\begin{tabular}{|c|c|c|c|}
\hline & \multicolumn{2}{|c|}{ Sexo-género } & \multirow[b]{2}{*}{ Total } \\
\hline Marcador & Hombres & Mujeres & \\
\hline ¿cachái? & $628(62,4 \%)$ & $246(24,3 \%)$ & $874(86,7 \%)$ \\
\hline ¿уа? & $27(2,7 \%)$ & $17(1,7 \%)$ & $44(4,4 \%)$ \\
\hline ¿a? & $10(1 \%)$ & $16(1,6 \%)$ & $26(2,6 \%)$ \\
\hline ¿no? & $7(0,7 \%)$ & $18(1,8 \%)$ & $25(2,5 \%)$ \\
\hline ¿me entiendes? & $2(0,2 \%)$ & $9(0,9 \%)$ & $11(1,1 \%)$ \\
\hline ¿no cierto? & $3(0,3 \%)$ & $7(0,7 \%)$ & $10(1 \%)$ \\
\hline ¿entiendes(dí)? & $1(0,1 \%)$ & $8(0,8 \%)$ & $9(0,9 \%)$ \\
\hline ¿cierto? & $1(0,1 \%)$ & $2(0,2 \%)$ & $3(0,3 \%)$ \\
\hline ¿viste? & $0(0 \%)$ & $2(0,2 \%)$ & $2(0,2 \%)$ \\
\hline ¿te has fijado? & $0(0 \%)$ & $1(0,1 \%)$ & $1(0,1 \%)$ \\
\hline ¿te fijas? & $0(0 \%)$ & $1(0,1 \%)$ & $1(0,1 \%)$ \\
\hline ¿sí? & $0(0 \%)$ & $1(0,1 \%)$ & $1(0,1 \%)$ \\
\hline Total & $679(67,5 \%)$ & $328(32,5 \%)$ & $1007(100 \%)$ \\
\hline
\end{tabular}


Gráfico 4: Porcentaje de frecuencia de los marcadores interrogativos de control de contacto según sexo-género

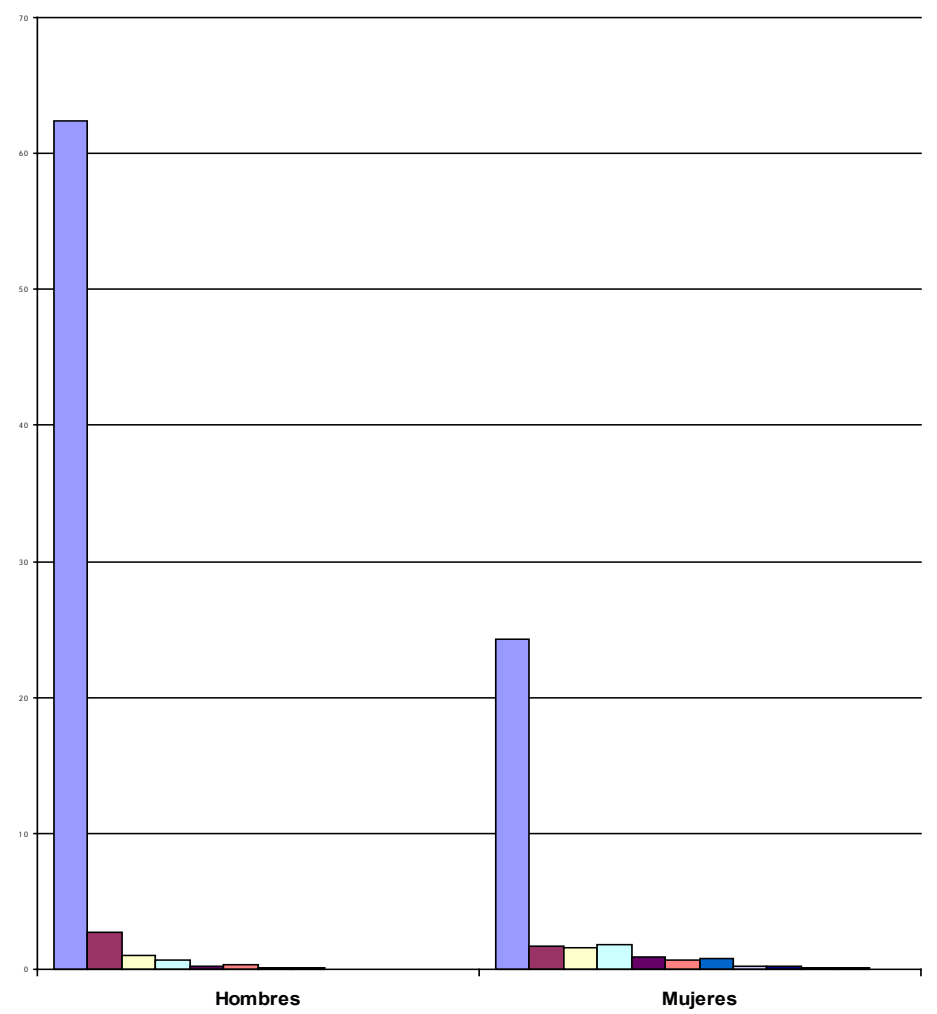

\begin{tabular}{|l|c|c|}
\hline & Hombres & Mujeres \\
\hline$\square_{\text {¿cachai? }}$ & 62,4 & 24,3 \\
\hline$\square_{\text {¿ya? }}$ & 2,7 & 1,7 \\
\hline$\square_{\text {¿a? }}$ & 1 & 1,6 \\
\hline$\square_{\text {¿no? }}$ & 0,7 & 1,8 \\
\hline$\square_{\text {¿me entiendes? }}$ & 0,2 & 0,9 \\
\hline$\square_{\text {¿no cierto? }}$ & 0,3 & 0,7 \\
\hline$\square_{\text {¿entiendes(dí)? }}$ & 0,1 & 0,8 \\
\hline$\square_{\text {¿cierto? }}$ & 0,1 & 0,2 \\
\hline$\square_{\text {¿viste? }}$ & 0 & 0,2 \\
\hline$\square_{\text {¿te has fijado? }}$ & 0 & 0,1 \\
\hline$\square_{\text {¿te fijas? }}$ & 0 & 0,1 \\
\hline$\square_{\text {¿sí? }}$ & 0 & 0 \\
\hline
\end{tabular}


En cuanto a los datos anteriores, resulta destacable que el marcador ¿cachái? se comporte como una partícula cuyo empleo es mayoritariamente masculino. Esto tiene un interés especial desde el punto de vista sociolingüístico, debido a que en el estudio de elementos periféricos como las muletillas y tag questions en inglés, el supuesto empleo mayoritariamente femenino de dichas partículas ha suscitado un interesante debate, desde que Lakoff (1975) interpretó el empleo de las muletillas y tag questions como un indicador de "inseguridad lingüística" por parte de las mujeres. No obstante, algunos estudios posteriores han corroborado que el uso de tales partículas discursivas no tiene necesariamente una relación con vacilaciones que sean indicadoras de inseguridad lingüística, sino que muchas veces se emplea con fines colaborativos, además de cuestionar su uso mayoritario por parte de mujeres (Coates 2009: 147-154).

Los datos de los que disponemos son en parte concordantes con los de Rabanales y Contreras (1995). Como ya señalamos más arriba, en su estudio general sobre las muletillas en el habla culta de Santiago, incluyendo los de función fática como los que aquí analizamos, dichos autores relevaron una mayor variedad y frecuencia de empleo de muletillas en hablantes jóvenes y de sexo masculino. En nuestro caso comprobamos un mayor uso de marcadores interrogativos de control de contacto por parte de los hombres, aunque existe una leve superioridad en las mujeres en cuanto a la variedad de unidades empleadas.

A nuestro juicio, el empleo mayoritario de ¿cachái? con la función de marcador interrogativo de control de contacto verificado en nuestros materiales podría interpretarse recurriendo al concepto de "prestigio encubierto" (covert prestige) que Labov (1966) acunara para referirse a las connotaciones positivas ocultas que reciben algunas formas no estándares o de estatus bajo (Trudgill y Hernández 2007: 254). En este sentido, ¿cachái? opera como un indicador de vernacularidad, ya que se trata de una partícula muy característica del habla chilena, indefectiblemente asociada a esta variedad de la lengua española, cuya proliferación incluso ha sido estigmatizada por los defensores de la norma culta o los puristas del idioma en Chile. En virtud del concepto de "prestigio encubierto" puede comprenderse su empleo preferentemente por los hablantes hombres del nivel educacional más bajo de la muestra. A este respecto, resulta aclaradora la siguiente afirmación de Coates (2009: 119):

Un resultado sólido de la investigación sociolingüística es que las mujeres -al igual que los hablantes de la clase media- utilizan proporcionalmente más formas estándares (a las que la sociedad atribuye un prestigio manifiesto) mientras que los hombres - junto con los hablantes de la clase trabajadora- utilizan en proporción más formas no estándares. 
Por supuesto, esto no quiere decir que el empleo de ¿cachái? como marcador interrogativo de control de contacto sea exclusivo de los hablantes hombres del nivel educacional más bajo, sino que se trata de la explicación sociolingüística más plausible para las diferencias de frecuencia de empleo relevadas en nuestro trabajo. Por último, su carácter decididamente más juvenil, así como la preferencia por su empleo en los niveles educacionales bajo y alto de la muestra, podrían ser indicadores de que el uso mayoritario de ¿cachái? como marcador interrogativo de control de contacto corresponde a un cambio lingüístico en marcha, en desmedro del empleo del resto de los marcadores que cumplen dicha función.

\section{CONCLUSIONES}

Las conclusiones más significativas del presente trabajo pueden sintetizarse como sigue:

1. En este estudio hemos considerado la función discursiva "Marcador interrogativo de control de contacto" como un caso de variable lingüística -en un sentido amplio del concepto- a nivel de discurso, cuyo empleo se analizó en un corpus de 54 entrevistas del Proyecto PRESEEA correspondientes a una muestra representativa del habla de Santiago de Chile.

2. En nuestro corpus se identificaron 1007 ocurrencias de empleo de la función discursiva antes señalada, la que se concretó mediante 12 variantes o valores con los siguiente números de ocurrencias y frecuencias de empleo: ¿cachái? (874 ocurrencias, 86,7\%), ¿ya? (44 casos, 4,4\%), ¿a? (26 ocurrencias, 2,6\%), ¿no? (25 casos, 2,5\%), ¿me entiendes? (11 ocurrencias, $1,1 \%)$ y ¿no cierto? (10 casos, $1 \%)$, ¿entiendes(di)? (nueve ocurrencias, 0,9\%), ¿cierto? (tres casos, 0,3\%), ¿viste? (dos ocurrencias, 0,2\%), ¿te has fijado?, ¿te fijas? y ¿sí? (un caso y $0,1 \%$, para cada uno).

3. Basándonos en la conmutabilidad funcional -pragmática y discursivade estas 12 partículas en la muestra de discurso en estudio, procedimos al análisis cuantitativo de su empleo, según las variables: edad, sexo y nivel educacional, verificando la notoria preponderancia de ¿cachái? con la función antes señalada, en contraste con las frecuencias de empleo de las otras 11 variantes, tal como se indica precedentemente. 
4. Los factores sociodemográficos que resultaron ser más sensibles en el empleo de los marcadores de control de contacto interrogativos relevados fueron la edad y el sexo-género de los sujetos cuyas entrevistas conformaron la muestra de discurso analizada.

5. El marcador interrogativo de control de contacto ¿cachái? está muy extendido en el habla de los sujetos más jóvenes de la muestra (entre 20 y 34 años), en especial, aunque no de modo exclusivo, entre los hablantes de sexo masculino. En nuestra opinión, tal vez, podría interpretarse la extensión del empleo de ¿cachái? como marcador interrogativo de control de contacto como un proceso de cambio lingüístico, en el cual dicho marcador parece estar desplazando a otras partículas que cumplen una función semejante. En apoyo a esta interpretación puede esgrimirse el factor edad como rasgo determinante. Asimismo, sería plausible interpretar la extensión del marcador ¿cachái? entre los hombres de la muestra a la luz del concepto de "prestigio encubierto", debido a su carácter vernáculo, puesto que se trata de una partícula característica del habla chilena actual desde el punto de vista diferencial.

6. Para finalizar, cabe destacar el carácter necesariamente relativo de las conclusiones aquí sintetizadas, ya que se trata del procesamiento de solo la mitad del corpus PRESEEA de Santiago de Chile.

\section{REFERENCIAS BIBLIOGRÁFICAS}

Bosque, Ignacio y Violeta Demonte (eds.). 1999. Gramática descriptiva de la lengua española (3 volúmenes). Madrid: Espasa.

Briz, ANTONIO. 2001. El español coloquial en la conversación: esbozo de pragmagramática. Barcelona: Ariel.

Carbonero, Pedro y María Teresa Palet (eds.). 1990. Sociolingüística Andaluza 5: habla de Sevilla y habas americanas. Sevilla: Secretariado de Publicaciones de la Universidad de Sevilla.

Carbonero, Pedro y Catalina Fuentes (eds.). 1993. Sociolingüística Andaluza 8: estudios sobre el enunciado oral. Sevilla: Secretariado de Publicaciones de la Universidad de Sevilla.

Carbonero, Pedro y Juana Santana. 2010. Marcadores del discurso, variación dialectal y variación social. En Loureda y Acín (coords.), pp. 497-521.

Casado Velarde. 1988. Lingüística del texto y marcadores del discurso. En María Martín Zorraquino y Estrella Durán (coords.), pp. 55-70.

COATES, JENNIFER. 2009. Mujeres, hombres y lenguaje. Un acercamiento sociolingüistico a las diferencias de género. México: Fondo de Cultura Económica. 
Cortés, Luis. 1988. Marcadores del discurso y análisis cuantitativo. En María Martín Zorraquino y Estrella Durán (coords.), pp. 143-160. Ágora. 1991. Sobre conectores, expletivos y muletillas en el español hablado. Málaga: 1995a. Bibliografía: marcadores del discurso (I). Español Actual 63: 63-82. 1995b. Bibliografía: marcadores del discurso (y II). Español Actual 64: 75-94.

DA: Asociación de ACAdemias de la Lengua Española. 2010. Diccionario de americanismos. Lima: Santillana Ediciones.

DRAE: Real Academia de la Lengua Española. 2001. Diccionario de la lengua española. Madrid: Espasa Calpe.

DUECH: Academia Chilena de la Lengua. 2010. Diccionario de uso del español de Chile. Santiago: MN Editorial.

Fuentes, Catalina. 1990a. Algunos Operadores de Función Fática. En Carbonero y Palet (eds.), pp. 137-150.

- 1990b. Apéndices con valor apelativo. En Carbonero y Palet (eds.), pp. 171-196. 1993. Claro: modalización y conexión. En Carbonero y Fuentes (eds.), pp. 99-126. 1996. La sintaxis de los relacionantes supraoracionales. Madrid: Arco/Libros.

García Vizcaíno, María José. 2005. El uso de los apéndices modalizadores ¿no? y ¿eh? en español peninsular, en Lotfi Sayahi y Maurice Westmoreland (eds.), Selected Proceedings of the Second Workshop on Spanish Sociolinguistics. Cascadilla Proceedings Project Somerville, MA. [En línea]. Disponible en: http://www.lingref.com/cpp/wss/2/paper1143. pdf [Consulta: 01/03/2011].

Gili Gaya, Samuel. 1972. Curso superior de sintaxis española. Barcelona: Bibliograf.

González, Carlos, Meneses, Alejandra y Viviana Unda. 2000. Análisis de la relación entre estructuras sintácticas y marcadores discursivos en la conversación semiespontánea de adolescentes santiaguinos. Formulación de un proyecto de investigación. Onomázein 5: 333-346.

JAKOBSON, Roman. 1975. Lingüística y poética. En Ensayos de lingüistica general, Barcelona: Seix Barral, pp. 347-395.

Lavandera, Beatriz. 1978. Where does the sociolinguistic variable stop? Language in Society 7: $171-182$

Labov, William. 1966. The Social Stratification of English in New York City. Washington, D.C.: Center for Applied Linguistics.

1972. Sociolinguistic Patterns. Philadelphia: University of Pennsylvania Press.

Lakoff, Robin. 1975. Language and Woman's Place. Nueva York: Harper and Row.

LENSKi, GeRHARDT. 1954. Status Crystallization: A Non-vertical Dimension of Social Status. American Sociological Review 19: 405-413.

1956. Social Participation on Status Crystallization. American Sociological Review 21: 458-464.

López Morales, Humberto. 1990. La sociolingüística actual. En Francisco Moreno Fernández (recopilador): 79-87.

2004. Sociolingüistica. Madrid: Gredos.

LOUREDA, ÓSCAR Y ESPERANZA Acín (coords.). 2010. Los estudios sobre marcadores del discurso, hoy. Madrid: Arco/Libros.

Martin, James y Peter White. 2005. The Language of Evaluation. Appraisal in English. NewYork: Palgrave.

Martín Zorraquino, María y Estrella Durán (coords.). 1988. Los marcadores del discurso. Teoría y análisis. Madrid: Arco/Libros. 
Martín Zorraquino, María y José Portolés. 1999. Los marcadores del discurso. En Ignacio Bosque y Violeta Demonte (eds.), pp. 4051-4207.

Meneses, AlejandRa. 2000. Marcadores discursivos en el evento "conversación". Onomázein 5: 315-331.

Móccero, María Leticia. 2010. Las preguntas confirmatorias como indicadoras de posicionamiento intersubjetivo. Estudios Filológicos 45: 67-78.

Moreno Fernández, Francisco (recop.). 1990. Estudios sobre variación lingüistica. Salamanca: Universidad de Alcalá de Henares, Servicio de Publicaciones.

1998. Principios de sociolingüistica y sociología del lenguaje. Barcelona: Ariel.

OBREGÓN, Hugo. 1985. Introducción a los marcadores interaccionales del habla dialogada en el español de Venezuela. Caracas: Centro de Investigaciones Lingüísticas y Literarias "Andrés Bello".

Ortega, Jenaro. 1985. Apéndices modalizadores en español: los "comprobativos", en Estudios románicos dedicados al profesor Andrés Soria Ortega, I. Granada: Universidad de Granada, pp. 239-255.

1986. Aproximación al mecanismo de la conversación: apéndices justificativos. Verba 13: 269-290.

Pérez, Mónica. 1998. Conectores discursivos en textos expositivos y argumentativos a nivel de parágrafo. Onomázein 3: 27-43.

Poblete, María Teresa. 1998. Los marcadores discursivo-conversacionales de más alta frecuencia en el español de Valdivia (Chile). Estudios Filológicos 33: 93-103.

1999. La cohesión de los marcadores discursivos en distintos tipos de discurso. Estudios Filológicos 34: 165-180.

Portolés, José. 2001. Marcadores del discurso. Barcelona: Ariel.

Pons, Hernán y José Luis SAmaniego. 1998. Marcadores pragmáticos de apoyo discursivo en el habla culta de Santiago de Chile. Onomázein 3: 11-25

Prieto Vera, Luis. 1995-1996. Análisis sociolingüístico del dequeísmo en el habla de Santiago de Chile. Boletín de Filología XXXV: 379-452.

Prieto Vera, Luis y Abelardo San Martín. 2002-2003. Diferencias de género en el empleo del discurso referido: aproximación sociolingüística y pragmático-discursiva. Boletín de Filología XXXIX: 269-303.

Rabanales, Ambrosio y Lidia Contreras. 1995. Las muletillas en el habla culta de Santiago de Chile. En Scripta Philologica in honorem Juan M. Lope Blanch, Vol. 2. México: UNAM, pp. 673-744.

Ramírez Gelbes, Silvia. 2003. La partícula “eh” y la Teoría de la Relevancia: Un ejemplo de contenido procedimental. Estudios Filológicos 38: 157-177.

RodRíguez, Yolanda. 1999. Marcadores discursivos en el habla de Barranquilla. Estudio sociolingüístico. Litterae. Revista de la Asociación de Exalumnos del Seminario Andrés Bello, No 8: 197-220.

Rodríguez, Francisco. 2009. Estudio sobre las funciones pragmadiscursivas de ¿no? y ¿eh? en el español hablado. Revista de Lingüistica Teórica y Aplicada 47 (1): 83-101.

SAN Martín, ABELARDo. 2004-2005. Igual como marcador discursivo en el habla de Santiago de Chile: función pragmático-discursiva y estratificación social de su empleo. Boletín de Filología XL: 201-232.

Schiffrin, Deborah. 1987. Discourse Markers. Cambridge: Cambridge University Press.

Serrano, María José. 1995. El uso de la verdad y pues como marcadores discursivos de respuesta. Español Actual 64: 5-16.

1999. Bueno como marcador discursivo de inicio de turno y contraposición. Internacional Journal of the Sociology of Language 14: 115-133. 
2001. The socio-communicative function of two discourse markers in Spanish. Estudios de Sociolingüistica 2/1: 101-122.

Silva-Corvalán, Carmen. 2001. Sociolingüística y pragmática del español. Washington, D. C.: Georgetown University Press.

Sinclair, John y Malcolm Coulthard. 1972. Towards and Analysis of Discourse. Oxford: Oxford University Press.

Sperber, Dan y Deidre Wilson. 1994. La relevancia. Madrid: Visor.

Stubbs, Michael. 1983. Discourse Analysis: The Sociolinguistic Analysis of Natural Language. Chicago: University of Chicago Press.

Trudgill, Peter y Juan Manuel Hernández Campoy. 2007. Diccionario de sociolingüística. Madrid: Gredos.

UrzÚa-Carmona, PaUla. 2006. El verbo “cachar” en el español coloquial de Chile. Onomázein 13: 97-107. 